
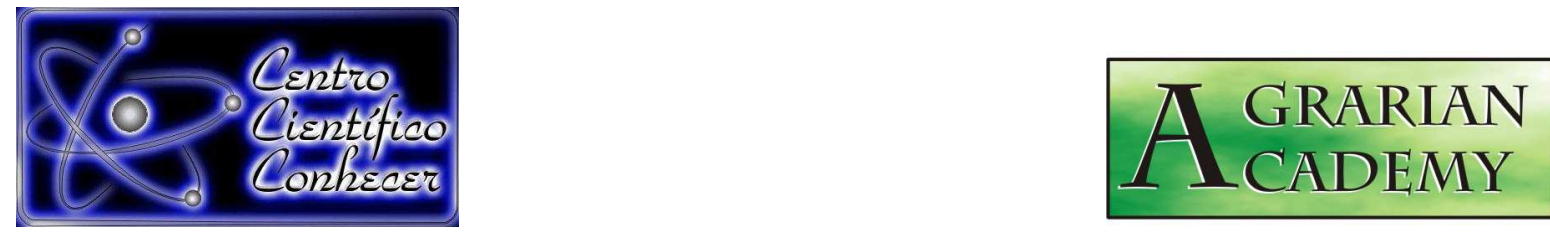

\title{
RESPOSTA À ADUBAÇÃO DE DUAS CULTIVARES DE AMENDOIM EM DOIS SISTEMAS DE SEMEADURA
}

Thalles Bernardino da Costa ${ }^{1}$; Francisco Edson da Silva ${ }^{2}$; Nerton da Penha Filho ${ }^{2}$; Nailson dos Santos Lopes ${ }^{2}$; Felipe Thomaz da Camara ${ }^{3}$

${ }^{1}$ Graduando em Agronomia na Universidade Federal do Cariri (UFCA), Crato-CE, Brasil (thallesbernardino@hotmail.com);

${ }^{2}$ Graduando em Agronomia na UFCA, Bolsista do PetAgronomia, Crato-CE, Brasil; 3 Professor Adjunto e Tutor do Pet Agronomia da UFCA, Crato-CE, Brasil.

Recebido em: 30/11/2017 - Aprovado em: 15/12/2017 - Publicado em: 31/12/2017 DOI: 10.18677/Agrarian Academy 2017b25

\begin{abstract}
RESUMO
A formação de um stand de plantas adequado é essencial para obter boa produtividade, com o mesmo sendo o resultado dos espaçamentos adotados, do uso de adubo químico e sistema de plantio, que pode influenciar negativamente na germinação das plantas. Desta forma, o objetivo deste trabalho foi avaliar o desempenho das cultivares BR1 e BRS151L7 submetidas a diferentes doses de adubação em dois sistemas de plantio. $O$ delineamento utilizado foi em blocos casualizados, em esquema fatorial $2 \times 2 \times 2$, com três repetições. $O$ primeiro fator foi 0 sistema de plantio (Sulco e Matraca), o segundo fator foi a adubação de semeadura (com e sem) e o terceiro fator a cultivar de amendoim (BR1 e BRS151L7). Durante a execução da pesquisa as variáveis analisadas foram a população inicial e final, a altura das plantas, número de vagens por planta, número de grãos por vagem, a massa de mil grãos, a produtividade de vagens e de grãos e o rendimento de grãos. O sistema de plantio em sulco foi o que apresentou maior população inicial e o melhor índice de sobrevivência enquanto a matraca apresentou maior número de vagens por planta. A adubação na semeadura e a cultivar BRS151L7 apresentaram maior número e vagens por planta, massa de 1000 grãos e produtividade em relação à ausência de adubo e a cultivar BR1, respectivamente.
\end{abstract}

PALAVRAS-CHAVE: Grãos, matraca; Produtividade;sulco; vagens;

\section{FERTILIZING RESPONSE OF TWO PEANUT CULTIVARS IN TWO SOWING SYSTEMS}

\section{ABSTRACT}

The formation of a suitable plant stand is essential to obtain good productivity, with the same being the result of the spacings adopted, the use of chemical fertilizer and planting system, which can negatively influence the germination of the plants. Thus, AGRARIAN ACADEMY, Centro Científico Conhecer - Goiânia, v.4, n.8; p. 2402017 
the objective of this work was to evaluate the performance of cultivars BR1 and BRS151L7 submitted to different doses of fertilization in two systems of planting. The experimental design was a randomized complete block design, in a 2x2x2 factorial scheme, with three replications. The first factor was the planting system (Sulco and Matraca), the second factor was sowing (with and without) and the third factor was the peanut cultivar (BR1 and BRS151L7). During the execution of the research the variables analyzed were the initial and final population, plant height, number of pods per plant, number of grains per pod, mass of one thousand grains, pod and grain yield and grain yield. The system of furrow planting showed the highest initial population and the best survival rate while the matraca presented the highest number of pods per plant. Fertilization at sowing and cultivar BRS151L7 showed higher numbers and pods per plant, mass of 1000 grains and productivity in relation to absence of fertilizer and cultivar BR1, respectively.

KEYWORDS: Productivity; green beans; grains; rattle.

\section{INTRODUÇÃO}

O Amendoim (Arachis hypogaea L.) é uma oleaginosa típica de climas quentes, adapta-se a uma ampla faixa climática, sendo cultivada em diversos países ao redor do mundo, nos hemisférios norte e sul, tanto por pequenos agricultores familiares como por produtores com alto nível tecnológico. É cultivado em todo território nacional. A produção aumentou expressivamente nos últimos anos, alcançando 350 mil toneladas em 2016 (CONAB, 2017).

No Brasil, o estado de São Paulo destaca-se como maior produtor, sendo responsável por $90 \%$ da produção nacional, seguido por Rio Grande do Sul $(2,7 \%)$, Minas Gerais $(1,8 \%)$ e Paraná $(1,2 \%)$. O Nordeste apresenta apenas $0,85 \%$ da produção nacional, tendo a participação dos Estados da seguinte forma: Ceará $(6,9 \%)$, Paraíba $(6,9)$, Sergipe $(45,8 \%)$, Bahia $(40,3 \%)$; segundo o levantamento da (CONAB, 2017).

O amendoim apresenta facilidade de desenvolvimento na maioria dos tipos de solos, mas apresenta melhor desempenho em solos bem drenados, férteis e de textura arenosa (BELTRÃO et al., 2011), o que favorece a penetração dos ginóforos ou "esporões" no solo.

Aliado à textura do solo, a nutrição das plantas está entre os fatores que pode influenciar na produtividade, tendo os macronutrientes nitrogênio, fósforo e potássio como os mais expressivos para o desenvolvimento da cultura. O nitrogênio tem grande influência na altura das plantas, no número de folhas, no diâmetro do caule e na massa seca das plantas (CORREIA, et al, 2012). O fósforo é crucial no metabolismo da planta, desta forma, este nutriente é importante no crescimento inicial das raízes e tem função básica na promoção de desenvolvimento de sementes (MARQUES, 2014). O potássio também tem alto grau de importância no desenvolvimento vegetal, pois é um controlador dos movimentos estomáticos e ativador metabólico essencial para formação de proteínas, mesmo não possuindo função estrutural ou metabólica (HESS, 2015).

Portanto, a disponibilidade dos nutrientes para a cultura no solo é fundamental para elevar a produtividade do amendoim, onde o arranjo das plantas, como espaçamento e formas de semeadura pode interferir na competição intraespecífica. A forma de semeadura mais utilizada no país é utilizando semeadoras de precisão, depositando as sementes com espaçamento desejado uma a uma. Entretanto, a produção de amendoim no Ceará pelos pequenos agricultores familiares é feita de forma bastante rudimentar, com uso de semeadoras manuais denominadas 
"matraca". A principal diferença entre os sistemas, é que a matraca deposita mais de uma semente por "cova" e a distância entre as covas são maiores, fato que influencia diretamente no arranjo das plantas e no desenvolvimento e produtividade da cultura. Desta forma, o objetivo deste trabalho foi avaliar o desempenho das cultivares BR1 e BRS151L7 em função da adubação mineral de semeadura em dois sistemas de plantio.

\section{MATERIAL E METODOS}

O experimento foi realizado no período de agosto a novembro de 2017, em regime irrigado por microaspersão, no Sítio Madeira Cortada, Missão Velha-CE, com as coordenadas geográficas $7^{\circ} 13^{\prime} 43^{\prime \prime S}$ e $39^{\circ} 10^{\prime} 40^{\prime \prime} \mathrm{W}$, a $350 \mathrm{~m}$ de altitude. O clima da região é tropical úmido, referente ao Aw, segundo a classificação climática de Köeppen, com inverno seco característico de maio a outubro, e estação chuvosa presente de novembro a abril. As precipitações são, geralmente, superiores a 750 mm por ano nestas regiões de clima Aw', sendo encontrado nas serras do Ceará (EMBRAPA 2016).

O solo da área experimental foi classificado como Latossolo Vermelho Amarelo distrófico típico, de textura média, conforme classificação do mapa de solos de média intensidade da FUNCEME (2012). A constituição química na camada de 0$20 \mathrm{~cm}$ foi: $\mathrm{pH}(1: 2,5 \mathrm{H} 2 \mathrm{O}): 7,0 ; \mathrm{P}\left(\right.$ melich $\left.^{-1}\right): 4,35 \mathrm{mg} \mathrm{dm}^{-3} ; \mathrm{K}: 1,90 \mathrm{mmolc} \mathrm{dm}^{-3}$; $\mathrm{Ca}$ : 22,4 mmolc dm${ }^{-3}$; Mg: 12,2 mmolc $\mathrm{dm}^{-3}$; CTC: $42,4 \mathrm{mmolc} \mathrm{dm}^{-3}$ e V (\%): 89.

$\mathrm{O}$ delineamento utilizado foi em blocos casualizados, em esquema fatorial $2 \times 2 \times 2$, com três repetições. O primeiro fator foi a forma de semeadura (Sulco e Matraca), o segundo fator foi a adubação de semeadura (com e sem) e o terceiro fator a cultivar de amendoim (BR1 e BRS151L7).

As parcelas consistiram em cinco fileiras espaçadas a $0,4 \mathrm{~m}$, com três metros de comprimento, totalizando uma área por parcela de $6 \mathrm{~m}^{2}(2 \times 3 \mathrm{~m})$. Foi considerada como parcela útil, apenas as três fileiras centrais com um metro de comprimento $(1,2$ $\mathrm{m}^{2}$ ), excluindo-se o restante, considerado como bordadura para reduzir o efeito dos tratamentos das parcelas próximas.

$\mathrm{Na}$ área experimental foi realizado o preparo do solo com arado de tração animal. Em seguida foram abertos sulcos com $10 \mathrm{~cm}$ de profundidade e com espaçamento entre fileiras de $0,4 \mathrm{~m}$ para todos os tratamentos. Foi realizada a adubação de semeadura com $500 \mathrm{~kg} \mathrm{ha}^{-1}$ da formulação 4-14-8 e adicionado solo sobre 0 adubo, para evitar o contato da semente com os adubos.

A semeadura foi realizada manualmente no dia três de agosto de 2017, de duas maneiras, conforme cada tratamento. Para a semeadura em sulcos, após a adubação de semeadura, adicionou-se solo sobre os adubos de forma a manter um pequeno sulco com aproximadamente $3 \mathrm{~cm}$ de profundidade, no qual foram depositadas as sementes manualmente, com espaçamento de $0,1 \mathrm{~m}$ entre as sementes, totalizando 10 sementes por metro, num total de $250.000 \mathrm{sem} \mathrm{ha}^{-1}$. Em seguida cobriu-se o sulco com solo.

Para a semeadura com matraca, uma semeadora manual muito utilizada por pequenos agricultores na região nordeste, que pode ser regulada para depositar por cova mais de uma semente, com esta quantidade sendo dependente do tamanho das sementes e da regulagem da abertura de saída das sementes. Nesta pesquisa, efetuou-se a regulagem para depositar duas sementes por cova, e visando manter a mesma quantidade de sementes por hectare, o espaçamento entre as covas foi de $0,2 \mathrm{~m}$. 
As cultivares de amendoim utilizadas foram a BR1 e a BRS151L7, duas cultivares desenvolvidas pela Embrapa para a região nordeste, de porte ereto e ciclo de 90 dias. O cultivo foi desenvolvido em sistema irrigado por microaspersão, com fileiras de micros localizadas a cada $3 \mathrm{~m}$, com vazão de $70 \mathrm{~L} \mathrm{~h}^{-1}$ por micro, totalizando uma vazão de $7,7 \mathrm{~mm} \mathrm{~h}^{-1}$. A irrigação foi realizada por uma hora diariamente.

Foram realizadas duas capinas manuais durante o desenvolvimento da cultura e a amontoa no florescimento, prática indispensável para a cultura de amendoim de porte ereto, caso das duas cultivares de amendoim utilizadas neste experimento. A colheita foi realizada no dia 03 de novembro de 2017, mantendo-se as plantas reviradas no campo, com as vagens voltadas para cima, para secagem durante o período de cinco dias. Neste período a irrigação foi suspensa.

Durante a execução da pesquisa, aos 21 dias após a semeadura (DAS), foi avaliada a população inicial, por meio da contagem do número de plantas emergidas em um metro de fileira, com os dados sendo convertidos para plantas ha ${ }^{-1}$. Pelo mesmo método, durante a colheita, foi calculada a população final. Relacionando-se a população final com a inicial, determinou-se o índice de sobrevivência.

As variáveis analisadas após a colheita foram a altura das plantas (Medida entre a superfície do solo e o ápice da planta), número de vagens por planta (Obtida após a contagem de todas as vagens da parcela útil e divisão pelo número de plantas contida na parcela útil), número de grãos por vagem (Após a separação dos grãos das vagens, realizou-se a contagem dos grãos e a divisão pelo número de vagens contidas na parcela útil), a massa de mil grãos (Determinada pela relação entre a massa pelo número de grãos e multipicado por mil), a produtividade de vagens e de grãos (Calculada pela extrapolação dos resultados de massa de vagens e de grãos da parcela útil para $\mathrm{kg} \mathrm{ha}^{-1}$ ) e o rendimento de grãos (Calculado pela relação entre a produtividade de grãos e de vagens). Os dados foram submetidos à análise de variância e os resultados significativos foram comparados pelo teste de tukey a $5 \%$ de probabilidade.

\section{RESULTADOS E DISCUSSÃO}

De acordo com a análise de variância dos dados encontrados no presente trabalho (Tabela 1), para o fator sistema de plantio, a altura das plantas foi a única variável não significativa $(p>0,05)$. Já a população inicial, população final e índice de sobrevivência foram significativos a $1 \%$ de probabilidade. No fator adubação, apenas a sobrevivência foi significativa $(p<0,01)$. Para as cultivares não foi verificada significância nas variáveis estudas. Não foi observada interação significativa entre os fatores em estudo.

Pelo teste de médias, nota-se que o sistema de semeadura em sulcos apresentou melhores resultados, pois além de proporcionar maior população inicial, ao fim do experimento notou-se $88,9 \%$ de sobrevivência, enquanto que por matraca, apenas $61,1 \%$ das plantas sobreviveram. Esta maior população inicial, deve-se principalmente ao melhor controle de deposição das sementes no sistema em sulcos, enquanto que na matraca, por possuir um sistema dosador rudimentar e de baixa precisão, mesmo regulando-se para depositar duas sementes por cova, frequentemente pode depositar apenas uma ou algumas vezes nenhuma semente, o que reduz a quantidade de sementes e consequentemente a população inicial.

Quanto ao menor índice de sobrevivência com uso de matraca, que reduz ainda mais a população final, o fator que mais influencia é a competição intraespecífica entre as plantas de amendoim, pois a colocação de duas sementes 
na mesma cova acentua a competição e morte de plantas durante o ciclo da cultura. Notou-se também, que no fator adubação apenas a variável sobrevivência, apresentou diferenciação entre os tratamentos. As parcelas com adubação atingiram apenas $66,8 \%$ de sobrevivência enquanto que as sem adubação chegaram a $83,3 \%$.

TABELA 1. Síntese da análise de variância e do teste de médias para a população inicial, população final, índice de sobrevivência e altura das plantas.

\begin{tabular}{|c|c|c|c|c|}
\hline $\begin{array}{c}\text { Fontes de } \\
\text { Variação }\end{array}$ & $\begin{array}{l}\text { População } \\
\text { Inicial }\end{array}$ & $\begin{array}{c}\text { População } \\
\text { Final } \\
\text { plantas ha-1 }\end{array}$ & $\begin{array}{c}\text { Sobrevivência } \\
\%\end{array}$ & $\begin{array}{c}\text { Altura } \\
\mathrm{cm}\end{array}$ \\
\hline $\begin{array}{c}\text { Sistema (S) } \\
\text { Adubação (A) } \\
\text { Cultivar (C) } \\
S^{\star} A \\
S^{\star} C \\
A^{*} C \\
S^{*} A^{\star} C\end{array}$ & $\begin{array}{l}9,38^{* *} \\
1,39^{N S} \\
2,72^{N S} \\
1,38^{N S} \\
2,72^{N S} \\
0,50^{N S} \\
0,05^{N S}\end{array}$ & $\begin{array}{l}\text { TES } \\
28,52^{* *} \\
2,52^{N S} \\
1,02^{N S} \\
0,18^{N S} \\
0,18^{N S} \\
1,02^{N S} \\
0,52^{N S}\end{array}$ & $\begin{array}{l}\text { E F } \\
25,86^{* *} \\
9,05^{* *} \\
0,21^{N S} \\
2,14^{N S} \\
0,23^{N S} \\
0,29 \text { NS } \\
0,99^{N S}\end{array}$ & $\begin{array}{l}0,14^{N S} \\
0,37^{N S} \\
0,07^{N S} \\
0,62^{N S} \\
1,15^{N S} \\
0,44^{N S} \\
0,92^{N S}\end{array}$ \\
\hline CV\% & 11,36 & 24,42 & 17,89 & 19,64 \\
\hline
\end{tabular}

TESTE DE TUKEY $(p<0,05)$

Sistema

$\begin{array}{ccccc}\text { Sulco } & 204.167 \mathrm{a} & 183.333 \mathrm{a} & 88,9 \mathrm{a} & 35,2 \mathrm{a} \\ \text { Matraca } & 177.083 \mathrm{~b} & 106.250 \mathrm{~b} & 61,1 \mathrm{~b} & 36,3 \mathrm{a}\end{array}$

Adubação

Com

185.417 a

156.250 a

$66,8 \mathrm{~b}$

34,8 a

Sem

195.833 a

133.333 a

83,2 a

36,6 a

Cultivar

$\begin{array}{lllll}\text { BR1 } & 197.917 a & 152.083 a & 76,3 a & 35,3 a \\ \text { RS151L7 } & 183.333 a & 137.500 a & 73,7 a & 36,1 \mathrm{a}\end{array}$

Médias seguidas pela mesma letra minúscula na coluna, não diferem entre si pelo teste de Tukey a $5 \%$ de probabilidade.

${ }^{* *}$ : significativo $(\mathrm{P}<0,01)$; ${ }^{*}$ : significativo $(\mathrm{P}<0,05)$; NS: não significativo; $\mathrm{CV} \%$ : coeficiente de variação

Para o fator cultivar, ao nível de $5 \%$ de probabilidade pelo teste de tukey, nenhuma das variáveis estudadas (população inicial, população final, sobrevivência e altura de planta) apresentou diferença significativa, em função de ambas terem sido desenvolvidas para a região, com boa resposta às condições climáticas da região nordeste. Entretanto, segundo Zerbato et al. (2015), sementes graúdas tendem a ter melhor emergência em função da maior reserva, apresentando grande população inicial e final, todavia, apesar da BRS151L7 apresentar sementes maiores do que a BR1, nesta pesquisa, ambas obtiveram valores similares de população.

Com relação à altura das plantas, não houve interferência dos fatores em estudo, com altura média de $35,9 \mathrm{~cm}$, valores próximos aos encontrados por Sousa et al. (2014) trabalhando com amendoim ereto na mesma região, no município de Fortaleza-CE, em função da frequência de irrigação, obtiveram maiores valores de 
altura para o intervalo de dois dias entre as irrigações, com altura de aproximadamente $38 \mathrm{~cm}$.

$\mathrm{Na}$ Tabela 2, verifica-se que a única variável que apresentou diferença significativa para todos os fatores foi o número de vagens por planta para os fatores sistema de plantio e adubação $(p<0,01)$, e cultivar $(p<0,05)$. Nota-se também que ocorreu interação significativa a $1 \%$ entre os sistemas de plantio e cultivares. Para as demais variáveis não ocorreu interação significativa entre os fatores, com a massa de mil grãos apresentando diferença significativa entre as cultivares, com a variedade BR1 tendo menor massa de mil grãos, característica esta inerente à cultivar, que apresenta grãos menores do que a BRS151L7.

TABELA 2. Síntese da análise de variância e do teste de médias para o número de vagens por planta (NV/P), número de grãos por vagem (NG/V), a massa de mil grãos (M1000G).

\begin{tabular}{|c|c|c|c|}
\hline Fontes de Variação & $\begin{array}{c}\text { NV/P } \\
\text { unidade }\end{array}$ & $\begin{array}{c}\text { NG/V } \\
\text { Unidade }\end{array}$ & $\begin{array}{c}\text { M1000G } \\
g\end{array}$ \\
\hline $\begin{array}{c}\text { Sistema (S) } \\
\text { Adubação (A) } \\
\text { Cultivar (C) } \\
S^{\star} A \\
S^{\star} C \\
A^{\star} C \\
S^{\star} A^{\star} C\end{array}$ & $\begin{array}{c}19,02^{* *} \\
9,01^{* *} \\
8,45^{*} \\
0,60^{\mathrm{NS}} \\
11,73^{* *} \\
0,16^{\mathrm{NS}} \\
4,14^{\mathrm{NS}} \\
\end{array}$ & $\begin{array}{l}\mathbf{F} \\
0,06 \text { NS } \\
0,06 \text { NS } \\
2,20^{N S} \\
1,13^{N S} \\
1,72 \text { NS } \\
0,00 \text { NS } \\
0,06 \text { NS }\end{array}$ & $\begin{array}{c}0,79^{N S} \\
0,00^{N S} \\
11,65^{* *} \\
0,08^{N S} \\
2,23^{N S} \\
1,05^{N S} \\
0,01^{N S}\end{array}$ \\
\hline CV\% & 28,18 & 27,39 & 14,02 \\
\hline
\end{tabular}

TESTE DE TUKEY $(p<0,05)$

\section{Sistema}

$\begin{array}{crrr}\text { Sulco } & 13,1 & 1,64 \mathrm{a} & 397 \mathrm{a} \\ \text { Matraca } & 21,9 & 1,69 \mathrm{a} & 417 \mathrm{a}\end{array}$

Adubação

$\begin{array}{llll}\text { Com } & 20,6 \mathrm{a} & 1,69 \mathrm{a} & 407 \mathrm{a} \\ \text { Sem } & 14,5 \mathrm{~b} & 1,65 \mathrm{a} & 407 \mathrm{a}\end{array}$

Cultivar

$\begin{array}{cccc}\text { BR1 } & 14,6 & 1,81 \mathrm{a} & 367 \mathrm{~b} \\ \text { BRS151L7 } & 20,5 & 1,53 \mathrm{a} & 447 \mathrm{a}\end{array}$

Médias seguidas pela mesma letra minúscula na coluna, não diferem entre si pelo teste de Tukey a $5 \%$ de probabilidade.

**: significativo $(P<0,01)$; *: significativo $(P<0,05)$; NS: não significativo; $C V \%$ : coeficiente de variação.

O número de vagens por planta apresentou altos valores com o uso de adubação de semeadura. Sousa et al., (2013) obtiveram resultados semelhantes quando testaram diferentes doses de adubação, com maiores produtividades quando o amendoim foi adubado.

Como os fatores sistema e adubação tiveram interação significativa, o desdobramento da interação para o número de vagens por planta está na Tabela 3 , observou-se que apenas a cultivar BRS151L7 apresentou maior número de vagens 
por planta no plantio com matraca, influenciado pela menor população final, fato que eleva a produção individual por planta, enquanto que a BR1 não apresentou essa produção que também era esperada. Já para o cultivo em sulcos, ambas cultivares apresentaram resultados semelhantes.

TABELA 3. Interação entre os fatores sistema de plantio e cultivar para a variável número de vagens por planta (unidade).

\begin{tabular}{ccc}
\hline Sistema & \multicolumn{2}{c}{ Cultivar } \\
\cline { 2 - 3 } & BR1 & BRS151L7 \\
\hline Sulcos & $13,7 \mathrm{aA}$ & $12,6 \mathrm{bA}$ \\
Matraca & $15,6 \mathrm{aB}$ & $28,3 \mathrm{aA}$ \\
\hline
\end{tabular}

Médias seguidas pela mesma letra minúscula nas colunas e maiúsculas nas linhas não diferem estatisticamente entre si segundo o teste de TuKey a $5 \%$ de probabilidade.

Os resultados de produtividade de vagens, produtividade de grãos e o rendimento de grãos estão expostos na Tabela 4. Nota-se que os sistemas de plantio não tiveram resultados significativos para todas as variáveis de produção, enquanto que a adubação e cultivar obtiveram diferenças significativas a $5 \%$ de probabilidade para a produtividade de vagens e de grãos de amendoim, com o rendimento de grãos sendo semelhante estatisticamente $(p>0,05)$.

Para os sistemas de plantio, nota-se que foram similares as produtividades entre o sistema em sulcos e matraca. Apesar do sistema em sulcos proporcionar maior população de plantas, a cultura do amendoim teve boa capacidade em aumentar a produção individual por planta, observado pelo maior número de vagens por planta para o sistema de matraca, o que contribuiu para manter similar a produtividade de vagens e grãos entre os sistemas.

O uso de adubo na semeadura aumentou a produtividade de grãos e de vagens (Tabela 4). Meneghette et al. (2017) obtiveram resultados semelhantes quanto ao uso da adubação fosfatada, com aumento na produtividade do amendoim. Para as cultivares, observa-se que a BRS151L7 foi mais produtiva, obtendo 26,0 e $30,6 \%$ a mais de produtividade de vagens e de grãos, respectivamente. Esta maior produtividade pode estar relacionada ao tamanho dos grãos. Zerbato et al. (2015) obtiveram valores elevados de produtividade para sementes maiores, confirmando esta tendência de produtividade para cultivares com sementes maiores.

TABELA 4. Síntese da análise de variância e do teste de médias para a produtividade de vagens (PV), a produtividade de grãos (PG) e 0 rendimento de grãos (Rendimento)

\begin{tabular}{|c|c|c|c|}
\hline Fontes de Variação & $\begin{array}{c}\text { PV } \\
\mathrm{kg} \mathrm{ha}^{-1}\end{array}$ & $\begin{array}{c}\text { PG } \\
\mathrm{kg} \mathrm{ha}^{-1}\end{array}$ & $\begin{array}{c}\text { Rendimento } \\
\%\end{array}$ \\
\hline $\begin{array}{c}\text { Sistema (S) } \\
\text { Adubação (A) } \\
\text { Cultivar (C) } \\
S^{\star} A \\
S^{\star} C \\
A^{\star} C \\
S^{\star} A^{\star} C\end{array}$ & $\begin{array}{c}0,07^{\text {NS }} \\
4,11^{*} \\
3,97^{*} \\
1,42^{\text {NS }} \\
2,76^{\text {NS }} \\
0,03^{N S} \\
0,92^{\text {NS }}\end{array}$ & $\begin{array}{c}\text { TESTE F } \\
0,00 \text { NS } \\
4,01 \text { * } \\
3,79 \text { * } \\
0,53 \text { NS } \\
2,79 \text { NS } \\
0,01 \text { NS } \\
0,77^{N S}\end{array}$ & $\begin{array}{l}0,89^{N S} \\
0,42 \text { NS } \\
0,00 \text { NS } \\
0,48 \text { NS } \\
0,06 \text { NS } \\
0,59 \text { NS } \\
0,01^{N S}\end{array}$ \\
\hline CV\% & 40,21 & 48,55 & 12,84 \\
\hline
\end{tabular}




\section{TESTE DE TUKEY $(p<0,05)$}

\section{Sistema}

$\begin{array}{cccc}\text { Sulco } & 2575 \mathrm{a} & 1554 \mathrm{a} & 59,2 \mathrm{a} \\ \text { Matraca } & 2460 \mathrm{a} & 1569 \mathrm{a} & 62,2 \mathrm{a}\end{array}$

\section{Adubação}

$\begin{array}{llll}\text { Com } & 2883 a & 1781 a & 61,7 a \\ \text { Sem } & 2154 b & 1341 b & 59,7 a\end{array}$

\section{Cultivar}

$\begin{array}{cccc}\text { BR1 } & 2228 \mathrm{~b} & 1354 \mathrm{~b} & 60,8 \mathrm{a} \\ \text { BRS151L7 } & 2808 \mathrm{a} & 1769 \mathrm{a} & 60,6 \mathrm{a}\end{array}$

Médias seguidas pela mesma letra minúscula na coluna, não diferem entre si pelo teste de Tukey a $5 \%$ de probabilidade. ${ }^{* *}$ : significativo $(P<0,01)$; *: significativo $(P<0,05)$; NS: não significativo; $C V \%$ : coeficiente de variação.

\section{CONCLUSÕES}

Em função dos dados, é possível concluir que o sistema de plantio em sulco proporciona maior população inicial e final, e maior índice de sobrevivência. Em contrapartida o sistema com matraca apresenta maior número de vagens por planta, com ambos os sistemas obtendo produtividades similares.

A adubação de semeadura não altera a população de plantas, porém eleva o número de vagens por planta e a produtividade em vagens e grãos. As cultivares avaliadas proporcionam a mesma população inicial e final de plantas, porém a BRS151L7 produz mais vagens por planta e maior massa de mil grãos, refletindo em maior produtividade de vagens e de grãos do que a BR1.

\section{AGRADECIMENTOS}

À Universidade Federal do Cariri (UFCA) pela concessão de bolsa de extensão ao primeiro autor vinculado à PROEX, e bolsas de estudo aos demais autores por meio do Programa de Educação Tutorial (Pet) da Agronomia, que possibilitaram a execução desta pesquisa.

\section{REFERÊNCIAS}

CONAB - Companhia Nacional de Abastecimento. $8^{\circ}$ levantamento da safra 2016/2017 de grãos. Disponível em: <http://www.conab.gov.br/OlalaCMS/uploads/arquivos/17_05_12_10_37_57_boletim _graos_maio_2017.pdf> Acesso em: 20 de nov. 2017.

BELTRÃO, N.E.M.; SOUSA JÚNIOR, S.P.; OLIVEIRA, M.I.P.; FIDELES FILHO, J.; SILVA, M.N.B. Ecofisiologia do amendoim. In: BELTRÃ̃, N.E.M.; OLIVEIRA, M.I.P (Eds). Ecofisiologia das culturas de algodão, amendoim, gergelim, mamona, pinhão-manso e sisal. Brasília, DF: Embrapa Informação Tecnológica, 2011. p.125162.

CORREIA, M.A.R; PADRO, R.M; ALMEIDA, T.B.F; PUGA, A.P; José Carlos BARBOSA, J.C; Avaliação da desordem nutricional de plantas de amendoim cultivadas em solução nutritiva suprimidas de macronutrientes. Scientia Agraria, Curitiba, v.13, n.1, p.21-28, 2012. 
EMBRAPA. Clima. < http://www.cnpf.embrapa.br/pesquisa/efb/clima.htm> acesso em, 20 de dezembro de 2017.

FUNCEME - Fundação Cearense de Meteorologia e Recursos Hídricos. Levantamento de reconhecimento de media intensidade dos solos da mesorregião do sul cearense. Fortaleza: FUNCEME, 2012.

HESS, L; Potássio com aminoácidos melhora o enchimento da cebola. Campo \& Negócios, Uberlândia, MG, ed 116, 2015.

MARQUES, D. J; BIANCHINI, H. C.; ROEWER L. A. Fosfito de potássio contribui para enchimento de grãos. Campo \& Negócios, Uberlândia, MG ed. 141, 2014.

MENEGHETTE H.H.A, LAZARINI E, BOSSOLANI J.W, PARRA L. F, HAYASHI F. K. Doses de fósforo e potássio em plantas de amendoim na presença e ausência de adubação foliar, Brazilian Journal of Biosystems Engineering, v. 11, n.2, p. 125134, 2017.

SOUSA G.G, AZEVEDO B.M ,OLIVEIRA J.R.R, MESQUITA T.O, VIANA T.O.A.V Adubação potássica aplicada por fertirrigação e pelo método convencional na cultura do amendoim, Revista Brasileira de Engenharia Agrícola e Ambiental, v.17, n.10, p.1055-1060, 2013.

SOUSA, G.G.; AZEVEDO, B.M. de; FERNANDES, C.N.V.; VIANA, T.V. de A.; SILVA, M.L.S. Growth, gas exchange and yield of peanut in frequency of irrigation. Revista Ciência Agronômica, v. 45, n. 1, p. 27-34, 2014. Disponível em: < http://www.scielo.br/pdf/rca/v45n1/04.pdf>. Acesso em 20 de nov. de 2017.

ZERBATO, C.; FURLANI, C.E.A., ALMEIDA, R.F.de; VOLTARELLI, M.A.; SILVA, V.F.A. Quality of peanut mechanical sowing in function of seeding density and size of the seeds. Engenharia Agrícola, v.35, n.4, p. 711-720, 2015. Disponível em: http://dx.doi.org/10.1590/1809-4430-Eng.Agric.v35n4p711-720/2015. doi: 10.1590/1809-4430. 